\title{
Empowering preadolescents with ABI through metacognition: Preliminary results of a randomized clinical trial
}

\author{
Lucia Willadino Braga ${ }^{\mathrm{a}, *}$, Luciana Rossi ${ }^{\mathrm{a}}$, Ana Luisa Lourenco Moretto ${ }^{\mathrm{a}}$, \\ Juliana Magalhaes da Silva ${ }^{\mathrm{a}}$ and Michael Cole ${ }^{\mathrm{b}}$ \\ ${ }^{a}$ SARAH Network of Neurorehabilitation Hospitals, Brazil \\ ${ }^{\mathrm{b}}$ Department of Cognitive Sciences, University of California at San Diego La Jolla, CA, USA
}

\begin{abstract}
Purpose: The aim of this randomized clinical trial study was to evaluate the efficacy of an intervention program based on social mediation, cooperative learning and metacognition (Metacognitive Dimension) in preadolescents with acquired brain injury (ABI).

Participants/Methods: Participants were 29 ABI preadolescents: 14 in the experimental group and 15 in the control group (average age, 10.4 y.o.; average time of lesion, 5.3 years). Evaluations were conducted 3 months after the start of the intervention, using the Evaluation Scale of Elementary School Learning Strategies (ESESLS) to assess metacognitive strategies, Self-Concept Scale for Children (SCSC) and Behavioral Rating Inventory of Executive Functions (BRIEF).

Results: The experimental group had superior outcomes to the control. The results of metacognitive strategies (ESESLS) and self-concept (SCSC) were better in the experimental than in the control group $(p<0.05)$. BRIEF did not reveal any significant differences between the groups, although we observed better results in the experimental group for 5 sub items of the scale, in the broader index and global executive composite score.

Conclusion: Three months of an intervention based on cooperative learning helped preadolescents with acquired brain injury develop metacognitive strategies and improve self-concept, thereby helping empower the preadolescents in their social relationships.
\end{abstract}

Keywords: Brain injuries - rehabilitation, randomized controlled trial, adolescent behavior, adolescent psychology, self-concept, executive function

\section{Introduction}

The SARAH Network of Neurorehabilitation Hospitals originally created the family-based methodology for children with acquired brain injury (ABI) three decades ago. Over the years, this methodology has evolved with ongoing research and clinical experience, adjusting to the changing needs of the child and family [2-9,29]. A randomized clinical trial showed that

${ }^{*}$ Corresponding author: Lucia Willadino Braga, SARAH Hospital, SMHS Quadra 501, Conjunto A, Terreo, 70.335-901 Brasilia, DF, Brazil. Tel.: +55 613319 1206; Fax: +55 613226 5280; E-mail: luciabraga@sarah.br. children with ABI rehabilitated with the participation of the family within the context of everyday routines had better cognitive and motor outcomes after one year of intervention than the children treated exclusively by professionals [8]. However, the role of the family in the development and daily life of the child starts to change in preadolescence, when friends become increasingly important.

The beginning of adolescence is marked by extensive social and emotional changes that impact the individual's relationship with family and friends, resulting in distinct challenges $[13,16,22]$. This phase is characterized by the acquisition of new cognitive, logical and hypothesis-forming abilities. There is greater in- 
terest in social relationships organized in peer groups. The combination of developmental changes leads to new ways of interacting with the parents; furthermore, preadolescents begin to spend twice as much extracurricular time with their peers than with their families [22]. ABI adolescents and young adults can have various problems caused by impulsiveness, aggression, social awkwardness and impaired social perception [30]. It is especially important, then, to develop an approach aimed at empowering them with selfregulating abilities before they mature into full adolescence.

To help preadolescents with ABI, we made several changes to the family-based methodology to create a new intervention approach more tailored to the specific needs of this stage of development and to prepare them for adolescence and the start of adult life. The new project centers on developing cooperative learning for preadolescents with $\mathrm{ABI}$, with a strong emphasis on community and peer relationships [10]. The initial foundation for this approach was based on concepts from the 5 th Dimension $\left(5^{\text {th }} \mathrm{D}\right)[11,12]$.

The 5 thD is a playworld model system created in San Diego, California among non-brain injured preadolescents of both sexes, with a range of ages, ethnicities, and social classes. The playworld is organized as a micro-culture in out-of-school, community-based settings frequented by children and youth $[11,12]$. Important contributors to the 5 thD are college undergraduates ("students") who are trained to interact with the preadolescents to promote joint learning. While the students are given the opportunity for practical, hands-on experience with development theories, the preadolescents are given the chance to grow and interact with more experienced pairs [12]. The program has shown good results in several countries [12], but, until now, the model had never been tested on a group of preadolescents with acquired brain injury.

The project that we created for preadolescents with ABI used many of the 5thD concepts, which were adapted to meet the special needs and challenges of this population. A special virtue of the 5 thD in this regard is that it is designed for modifiability to specific populations and local circumstances. This new project is called Metacognitive Dimension (MCD) and aims to enrich and stimulate the social, academic, intellectual, and neuropsychological development of preadolescents with ABI, empowering them through metacognition. Metacognition describes individuals' ability to track their cognitive processing and comprises both knowledge and experience; it can lead to learning selfregulation and other cognitive functions [28].
The involvement of college undergraduates in the project is fundamental to stimulating metacognition. In the Metacognitive Dimension, these are students majoring in psychology and teaching. They are taught the basic concepts of mediation, metacognition and learning, and are supervised in their MCD activities by qualified professionals from the SARAH rehabilitation center's multidisciplinary team. These students are important; because of their age and experience, they share a similar vocabulary and range of interests with the preadolescents in the project. Students just starting college are particularly appropriate "more capable peers": they are closer in age to the preadolescents and consequently better satisfy the "more capable peer" requirement than older students, who might instead identify with the parents or professional staff.

The students are instructed in how to deploy the concept of cooperative learning, which refers to instructional methods in which pairs or small groups collaborate to accomplish a shared goal $[20,25]$. The aim of this cooperation is for individuals to maximize their own and each other's learning, with members striving for joint benefit [21]. Interactions with the students stimulate a variety of cognitive and social functions including metacognition, thereby helping the preadolescents reflect on their thought processes and behavior.

To test the hypotheses that the MCD intervention is better at promoting self-esteem and the development of metacognition than the traditional approach to preadolescents with $\mathrm{ABI}$, we conducted a randomized clinical trial comparing the groups.

\section{Methods}

\subsection{Participants}

Participants were 29 preadolescents with ABI in treatment at the SARAH Network of Neurorehabilitation Hospitals in Brazil, with an average time of 5.3 years since the injury. At recruitment the preadolescents were attending school and involved in longitudinal follow-up by the rehabilitation team, within the family based approach. Inclusion criteria were: (1) ages between 9 and 13 years old; (2) history of moderate or severe ABI on the Glasgow Coma Scale (GCS) [19]; (3) ABI onset at least 12 months prior to study (i.e., chronic stage); (4) scores in 2 Broader Indexes of the Behavior Rating Inventory of Executive Function (BRIEF) [17]: $\mathrm{t}$ Score of the Behavioral Regulation Index $\geqslant 50$ and $t$ Score of the Metacogni- 
Table 1

Characteristics of participants*

\begin{tabular}{lcc}
\hline & \multicolumn{2}{c}{ Groups } \\
\cline { 2 - 3 } Characteristics & $\begin{array}{c}\text { Experimental } \\
\mathrm{n}=14\end{array}$ & $\begin{array}{c}\text { Control } \\
\mathrm{n}=15\end{array}$ \\
\hline Gender (female/male) & $5 / 9$ & $3 / 12$ \\
Age at start of study (years) & $10.3(2.1)$ & $10.5(1.8)$ \\
Age at brain injury onset (years) & $4.8(3.0)$ & $5.4(2.4)$ \\
Time lapsed since brain injury (years) & $5.5(3.3)$ & $5.1(2.4)$ \\
Family's average monthly income (dollars) & $789(353)$ & $865(397)$ \\
Glasgow score at brain injury onset & $9.4(3.4)$ & $9.1(2.7)$ \\
BRIEF: Behavioral Regulation Index & $65.2(12.8)$ & $58.3(9.5)$ \\
BRIEF: Metacognition Index & $64.9(9.1)$ & $59.8(9.9)$ \\
Motor impairment, $\mathrm{n}$ & & 10 \\
$\quad$ None & 7 & 1 \\
Monoparesis & 3 & 3 \\
$\quad$ Hemiparesis & 3 & 1 \\
$\quad$ Tetraparesis & 1 & \\
\hline Unless otherwise stated, the values are means and standard deviations (SD); \\
$\mathrm{n}$ - number of child.
\end{tabular}

Table 2

tion Index $\geqslant 50$. Exclusion criteria were: (1) relevant sensorial disorders; (2) unresponsive state; (3) serious neuropsychiatric diagnosis; (4) motor or neuropsychological impairments that preclude assessment tests.

From October 2010 through February 2011, 45 patients were considered; 29 fulfilled the inclusion criteria and were followed up from February to April 2011. Subjects were randomly assigned to either the MCD intervention program $(n=14)$ or to a control group $(n=$ 15 ). The groups were homogenous; there was no difference in any of the characteristics, thereby confirming the effectiveness of the randomization (Table 1).

A majority (83\%) had MRIs done on a 3.0 Tesla scanner (Magnetom Trio, Siemens). Several preadolescents $(17 \%)$ were unable to submit to an MRI due to behavioral problems; in these cases, CT scans (Mx8000, Multislice CT Imaging System, Phillips) were conducted. The most frequent traumatic injuries affected the frontal region of the brain, followed by the temporal area and corpus callosum. There was no significant difference in lesion between the groups (Table 2).

\subsection{Procedures}

\subsubsection{Intervention group}

The preadolescents of the experimental group participated in the Metacognitive Dimension (MCD) program, the version of the 5 thD evolved at SARAH. In this case, college students majoring in psychology or teaching acted as the more capable peers. The students and preadolescents generally worked in pairs, sometimes forming small groups. The student/preadolescent pair planned and executed a series of diverse tasks,
Neuroimaging evaluation: frequency of children with lesions in each given location, by treatment groups*

\begin{tabular}{lcc}
\hline & \multicolumn{2}{c}{ Groups } \\
\cline { 2 - 3 } & $\begin{array}{c}\text { Experimental } \\
\mathrm{n}(\%)\end{array}$ & $\begin{array}{c}\text { Control } \\
\mathrm{n}(\%)\end{array}$ \\
\hline Frontal & & \\
Right & $5(36)$ & $4(27)$ \\
Left & $4(29)$ & $5(33)$ \\
Occipital & $2(14)$ & $3(20)$ \\
Temporal & & \\
Right & $3(21)$ & $4(27)$ \\
Left & $1(7)$ & $2(13)$ \\
Parietal & & \\
Right & $1(7)$ & $1(7)$ \\
Left & $1(7)$ & $2(13)$ \\
Brainstem & $1(7)$ & $1(7)$ \\
Cerebellum & $3(21)$ & $4(27)$ \\
Corpus callosum & $4(29)$ & $5(33)$ \\
Basal nuclei & & $1(7)$ \\
Right & $2(14)$ & $2(13)$ \\
Left & $1(7)$ &
\end{tabular}

$\mathrm{n}$ - number of child; $\%$ - percentage relative to the number of participants in the study group.

* There are no significant differences between groups.

Note: subject may present lesion in more then one location.

such as computer or board games, artistic or physical activities.

The students deployed deliberate mediational strategies to foster the preadolescent's neuropsychological development and metacognition. For example, if the preadolescent asked the student a specific question, the student would not simply answer; instead, he/she would reformulate the question and pose it back to the preadolescent. If needed, the student provided suggestions to help the less experienced partner (the preadolescent) 
Table 3

Self-Concept Scale for Children (SCSC)

\begin{tabular}{lccc}
\hline Primary outcomes: by overall score and by domain & \multicolumn{2}{c}{ Group } & p-value* \\
\cline { 2 - 3 } & $\begin{array}{c}\text { Experimental } \\
\text { mean (sd) }\end{array}$ & $\begin{array}{c}\text { Control } \\
\text { mean (sd) }\end{array}$ \\
\hline Self-Concept Scale for Children & $58(18.8)$ & $42(20.4)$ & 0.043 \\
Personal self-concept & $62(16.5)$ & $45(23.5)$ & 0.055 \\
Academic self-concept & $60(19.2)$ & $38(18.6)$ & 0.009 \\
Family self-concept & $61(19.3)$ & $43(17.6)$ & 0.029 \\
Social self-concept & $50(22.8)$ & $42(22.5)$ & 0.314 \\
\hline sd - standard deviation. & & & \\
$*$ Mann-Whitney. & & &
\end{tabular}

explore possibilities [25]. All interactions were based on cooperative learning, that is, on jointly "constructing" development.

The preadolescents in this group came to the center 2 afternoons a week and participated in the playworld activities mediated by the college students and rehabilitation team. They engaged in these activities for two hours every visit. There were a total of 26 sessions over a three-month period.

At the end of each afternoon's activities, the students and professionals gathered to discuss clinical aspects and exchanges, propose ideas, and make suggestions for the project. In addition, the rehabilitation team prompted the students to theoretical and practical reflections by leading the discussions and encouraging them to engage their growing knowledge and observations.

\subsection{Control group}

The preadolescents in this group continued to be treated according to the guidelines of the family-based approach, and underwent individual periodic reviews with the multidisciplinary team at the rehabilitation center $[8,9]$.

\subsubsection{Measures}

After 3 months of intervention, the preadolescents in both groups were evaluated. Each outcome was analyzed according to the intention-to-treat principle.

The two primary outcome measures were 1) SelfConcept Scale for Children (SCSC) [24]; and 2) Evaluation Scale of Elementary School Learning Strategies (ESESLS) [23] that assessed the metacognitive learning strategies. Both scales were standardized on the Brazilian population.

Before starting the study, the parents answered the Behavioral Rating Inventory of Executive Functions (BRIEF) questionnaire, used to evaluate executive function and behavior in the home environment, as well as inclusion criteria. After 3 months of intervention, this questionnaire was given to the parents again as secondary outcomes. The professionals that conducted these assessments were not part of the intervention teams; rather, they worked on other SARAH programs or at other SARAH hospitals. The SARAH Network Ethics Committee approved the research protocol and all proxies gave their written informed consent to participate in the trial.

\subsubsection{Data analysis}

Fisher's Exact and Mann-Whitney tests were used to check differences between the groups at baseline. The Mann-Whitney also analyzed the primary outcomes (metacognition - SCSC and ESESLS) obtained only after the intervention period, taking our hypothesis into account. The unique variable measured before and after the intervention was the BRIEF questionnaire, considered exclusion criteria at baseline and as secondary outcomes at the end of the study. Statistical significance for these analyses was $p<0.05$.

\section{Results}

There were significant differences between the experimental and control groups on the Self-Concept Scale for Children (SCSC) and the Evaluation Scale of Elementary School Learning Strategies (ESESLS). After 3 months, the experimental group presented higher averages than the control group in both the SCSC and ESESLS.

The preadolescents in the experimental group obtained an average 58-point overall score on the SCSC scale (Table 3 ), significantly better than the control group's average of 42 points $(p=0.043)$. In all of the SCSC sub items, the experimental group had a point average superior to the control group, with statistical significance in the academic self-concept $(p=0.009)$ and family self-concept ( $p=0.029)$ sub items. 
Table 4

Evaluation Scale of Elementary School Learning Strategies (ESESLS)

\begin{tabular}{lccc}
\hline Primary outcomes: By overall score and by domain & \multicolumn{2}{c}{ Group } & p-value* \\
\cline { 2 - 3 } & $\begin{array}{c}\text { Experimental } \\
\text { mean (sd) }\end{array}$ & $\begin{array}{c}\text { Control } \\
\text { mean (sd) }\end{array}$ \\
\hline Evaluation Scale of Elementary School Learning Strategies & $52(28.4)$ & $29(28.5)$ & 0.033 \\
Absence of dysfunctional strategies & $58(27.6)$ & $27(23.9)$ & 0.003 \\
Cognitive strategies & $39(26.9)$ & $34(22.6)$ & 0.660 \\
Metacognitive strategies & $56(29.9)$ & $25(20.0)$ & 0.003 \\
\hline
\end{tabular}

sd - standard deviation.

* Mann-Whitney.

On the ESESLS scale (Table 4), the experimental group obtained an average 52 points, while the control group had a significantly inferior average of 29 points $(p=0.033)$. In the ESESLS sub items, the experimental group always had better performance, with a significant difference between the groups in the sub items "absence of dysfunctional strategies" ( $p=0.003)$ and "metacognitive strategies" ( $p=0.003)$.

BRIEF was used to compare the differences between the parents' rating in the two groups, pre and postintervention. No differences between the groups were observed. However, the experimental group had better scores (which in the BRIEF were expressed by a reduction in the $\mathrm{t}$ score), on the Global Executive Composite and on the 2 Broader Index, Behavioral Regulation Index and Metacognition Index. In the domains Shift, Emotional Control, Initiate, Working Memory, and Plan/Organize, the experimental group also obtained greater improvement in parental ratings but, possibly because of the small sample size, these differences were not significant (Table 5).

\section{Discussion}

We decided to conduct this randomized clinical trial because there was no previously published evidence that an intervention program based on social mediation, cooperative learning and metacognition (Metacognitive Dimension) can help preadolescents with ABI improve their cognitive strategies and self-concept. After only three months, the group that participated in the intervention program presented more gains than the control group in metacognitive strategies (planning, monitoring and regulating behavior) and absence of dysfunctional strategies (use of strategies not very effective for the given setting or situation), as assessed by the Evaluation Scale of Elementary School Learning Strategies (ESESLS). The Self-Concept Scale for Children (SCSC) also showed better outcomes in the experimental group than in the control. Comparison of parental rat-
Table 5

BRIEF results (t score): improvement in three months (second evaluation minus first evaluation)*

\begin{tabular}{lcc}
\hline BRIEF domains & $\begin{array}{c}\text { Experimental } \\
\text { group } \\
\text { mean }(\mathrm{sd})\end{array}$ & $\begin{array}{c}\text { Control } \\
\text { group } \\
\text { mean }(\mathrm{sd})\end{array}$ \\
\hline Behavioral Regulation Index & $-1.1(7.5)$ & $4.1(12.4)$ \\
Inhibit & $0.1(11.3)$ & $-1.3(10.0)$ \\
Shift & $-1.3(9.9)$ & $3.7(14.2)$ \\
Emotional Control & $-2.4(8.1)$ & $2.2(12.3)$ \\
Metacognition Index & $-0.3(8.9)$ & $2.2(7.6)$ \\
Initiate & $-3.3(12.5)$ & $2.9(6.7)$ \\
Working Memory & $-1.4(5.3)$ & $2.0(8.3)$ \\
Plan/Organize & $-1.3(8.4)$ & $3.1(10.7)$ \\
Org of Materials & $3.7(15.3)$ & $1.5(10.4)$ \\
Monitor & $1.4(11.8)$ & $2.1(11.7)$ \\
Global Executive Composite & $-1.5(7.9)$ & $3.0(7.4)$ \\
\hline
\end{tabular}

sd - standard deviation.

* There are no significant differences between groups.

ings between the two groups on BRIEF, pre- and three months post-intervention, did not reveal any statistically significant differences, perhaps due to the sample size. Nevertheless, the experimental group had a trend of better results in the Global Executive Composite and on the 2 Broader Index, Behavioral Regulation Index and Metacognition Index. Parents of the experimental group also reported better improvement in the Shift, Emotional Control, Initiate, Working Memory, and Plan/Organize domains.

\subsection{Metacognitive Dimension program}

Cooperative learning, used in MCD, is based on peer interactions aimed at collaborative learning in social settings $[20,21,25,26]$. Student mediation, even if for a relatively short period of time, allowed the preadolescents with ABI to develop metacognitive strategies. They learned to think about their own thought processes and behavior, which facilitated self-regulation and self-control, and improved social relationships. An intervention that helps empower children with ABI during preadolescence contributes significantly in preparing them for the future. This is particularly important 
because some of the effects of the lesion manifest only in the adolescent years, mimicking a "latent injury". Insults to the frontal lobe during childhood or preadolescence may be relatively non-obvious because the frontal lobe is still developmentally silent, and the impact often appears several years later, especially with regards to behavior [15]. The neuropathology mixes with growing complex social and academic demands, increasing the behavioral difficulties faced by these individuals.

As noted by Ylvisaker and Feeney [27,28], better metacognition in a child with ABI fosters improvement in other cognitive functions as well as self-regulation. Self-concept (measured by SCSC) is a fundamental aspect of preadolescent development; it helps improve learning $[14,18]$. There appears to be a correlation between metacognition and self-concept.

We are currently working on another study that is being developed with the experimental (MCD) and control groups, in which we analyze the qualitative data of the Metacognitive Dimension program. For that study, interviews with these preadolescents were conducted using open-ended questions 3 months postintervention, and the results are currently undergoing analysis. It seemed relevant, however, to include some of the responses to help qualitatively illustrate the gains and empowerment that the preadolescents obtained from their experience in the MCD group: a) Self-concept/self-esteem: "I said to myself that I could be a better person and I did it. I started getting better grades. I started to like myself more in MCD"; b) Metacognition/Self-control: "I used to hug everybody in school; I really liked hugging the girls. But I started seeing that was wrong, that I should ask first if I can give someone a hug"; c) Plan/organize: "I got a small pad and began writing what I had to do, and putting the reminders where I could see them, where I go often, my bedroom"; d) Social skills: "I realized that all I had to do was ask, like if I want to play I just have to ask a friend if he wants to, and we can do it together. It's simple."

\subsection{Methodological limitations}

This study has several limitations. We began this investigation to analyze the effectiveness of the Metacognitive Dimension, as there were no data in the literature to guide more precise calculations about sample size or the best scales for evaluating the changes in preadolescents with $\mathrm{ABI}$ in this type of intervention. It was designed as a pilot study; as such, the randomization was simple, the time of intervention was short, and few pre and post-intervention measures were employed.

The SCSC and ESESLS scales were not used prior to the intervention. However, the probability that the groups differed in the aspects measured by those scales is very low, since both the experimental and the control groups were shown to be homogenous in all other aspects studied. The results were so promising that we decided to share, even if preliminarily, the initial findings with the scientific community. Furthermore, the preliminary results have allowed us to improve the randomized clinical trial, by pointing to the need for a larger sample and more tools for measuring results; these will be included in the next steps of assessing the preadolescents in this clinical trial.

Nevertheless, despite its limitations, the initial findings of this study show that an intervention using mediated activity, such as the Metacognitive Dimension program, fosters the improvement of metacognition, self-concept, and self-regulation: the preadolescents become more empowered in their social relationships and interactions with peers. This empowerment helps them make sense of themselves and their world, which is very important to their future [1].

\subsection{Impact and perspectives}

In most rehabilitation programs, preadolescents with ABI are seen by qualified rehabilitation professionals who focus on specific disorders (e.g., behavior, learning, communication, etc.) that are observable throughout the course of development. The MCD approach offers the possibility of improving aspects, such as selfesteem and metacognition, which generalize to other situations, such as daily life and social relationships. In addition to the results obtained with the preadolescents with chronic ABI, we also observed, with the MCD program, that the integration of the college students was very productive. The students optimized the rehabilitation team's work, increasing the number of patients that could be treated by a smaller team of professionals while, at the same time, giving the young students, tomorrow's practitioners, an opportunity to experience theories in practice under supervision and, consequently, improving their learning process. The participation of students obviously reduces the costs of the intervention, but most importantly, they are capable of doing more than the multidisciplinary team if they are well supervised, because they have the vocabulary and interests that allow them to become more experienced peers in this type of approach. 
The preliminary results of this study suggest the hypothesis that an intervention capable of stimulating metacognition and self-regulation during preadolescence can help prevent future problems in social behavior in later adolescence and young adulthood. In the concept of "latent injury" in ABI [15], these preadolescents require longitudinal follow-up. We will expand the sample and continue the randomized controlled trial to verify the consistency of these initial data. If confirmed, this methodology can be implemented at other institutions that treat preadolescents with ABI.

\section{Acknowledgments}

The authors would like to thank the following individuals for their contributions to the article: Paulo Sergio Siebra Beraldo; Luiz Guilherme Nadal Nunes; Eliana Valverde Magro Borigato; Yana Senna Jeronymo Najjar; Olinda Paula Azevedo; Luciana Balduino Sollaci; Claudia Ribeiro de Araujo Paulino; Patricia Franco Assunção; Carolina Alves Rezende Alcântara; Adriana Gonçalves da Silva; Adriana Luna Leitão; Elaine Soares Arima Juliana Borges dos Santos

\section{References}

[1] Arnold, J. (1992, November). A curriculum to empower young adolescents. Annual Meeting of the National Middle School Association. San Antonio, TX. [On-line] Available: http:// www.eric.ed.gov/PDFS/ED361913.pdf.

[2] Braga, L. W. (1983). O desenvolvimento cognitivo na paralisia cerebral: um estudo exploratório. Unpublished master's thesis, University of Brasília, Brasília, Brazil.

[3] Braga, L. W. (1986). Efeitos do processo de ensino/apren dizagem dos pais no desenvolvimento da criança com paralisia cerebral. Anais do Seminário A pesquisa em educação no Distrito Federal.

[4] Braga, L. W. (1994). Cognição em criança coreoatetóide. Unpublished doctoral dissertation, University of Brasília, Brasília, Brazil.

[5] Braga, L. W. (1995). Cognição de paralisia cerebral: Piaget e Vygotsky em questão. Salvador: Sarah Letras.

[6] Braga, L. W., \& Campos da Paz Jr, A. (2000). Neuropsychological pediatric rehabilitation. In A.L.Christensen \& B.P Uzzell (Eds), International handbook of neurological rehabilitation. (pp. 283-295). New York: Kluwer Academic.

[7] Braga, L. W. (2000). Family participation in the rehabilitation of the child with traumatic brain injury. Journal of the International Neuropsychological Society, 6:409.

[8] Braga, L. W., Campos da Paz Jr, A., \& Ylvisaker, M. (2005). Direct clinician-delivered versus indirect family-supported rehabilitation of children with traumatic brain injury: a randomized controlled trial. Brain Injury, 19, 819-831.
[9] Braga, L. W., \& Campos da Paz Jr, A. (2006). The child with traumatic brain injury or cerebral palsy: a context-sensitive, family-based approach to development. Oxon: Taylor \& Francis.

[10] Braga, L. W., Rossi, L., \& Cole, M. (2010). Creating an idioculture to promote the developmentof children with cerebral palsy. Educação e Pesquisa, 36, 131-141.

[11] Cole, M. (1996). Cultural psychology: a once and future discipline. Cambridge: The Belknap Press of Harvard University Press.

[12] Cole, M. (2006). The fifth dimension: an after-school program built on diversity. New York: Russel Sage.

[13] Dolgin, K. (2010). The Adolescent: development, relationships, and culture. (13th ed.). Upper Saddle River, NJ: Prentice Hall.

[14] Eccles, J.S., Wigfield, A., Flanagan, C.A., Miller, C., Reuman, D.A., \& Yee, D. (1989).Self-concepts, domain values, and self-esteem: relations and changes at early adolescence. Journal of Personality, 57, 283-310.

[15] Forsyth, R. J. (2010). Back to the future: rehabilitation of children after brain injury. Archives of Disease in Childhood, 95, 554-559.

[16] Garrod, A., Smulyan, L., Powers, S., \& Kilkenny, R. (2007). Adolescent portraits: identity, relationships and challenges. (6th ed.). Boston: Allyn \& Bacon.

[17] Gioia, G., Isquith, P., Guy, S., \& Kenworthy, L. (2000). Behavior Rating Inventory of Executive Function - BRIEF. Lutz,FL: Psychological Assessement Resources.

[18] Harter, S., \& Monsour, A. (1992). Development analysis of conflict caused by opposing attributes in the adolescent selfportrait. Developmental Psychology, 28, 251-260.

[19] Jennett, B., Snoek, J., Bond, M.R., \& Brooks, N. Disability after severe head injury: observations on the use of the Glasgow Outcome Scale. (1981). Journal of Neurology, Neurosurgery and Psychiatry, 44, 285-293.

[20] Johnson, D. W., Johnson, R. T., \& Smith, K. A. (1991). Cooperative learning : increasing college faculty instructional productivity. Washington, DC: School of Education and Human Development, George Washington University.

[21] Kagan, S. (1994). Cooperative learning. San Clemente: Kagan.

[22] Lightfoot, C., Cole, M., \& Cole, S. (2008). The development of children. (6th ed.). New York: Worth Publishers.

[23] Oliveira, K. L., Boruchovitch, E., \& Santos, A. A. (2010). Escala de avaliação das estratégias de aprendizagem para o ensino fundamental - EAVAP-EF [Evaluation Scale of Elementary School Learning Strategies - ESESLS]. São Paulo: Casa do Psicólogo.

[24] Sisto, F.F., \& Martinelli, S.C. (2004). Escala de auto-conceito infanto juvenil - EAC - IJ [Self-Concept Scale for Children (SCSC]. São Paulo: Vetor Editora.

[25] Tsay, M., \& Brady, M. (2010). A case study of cooperative learning and communication pedagogy: does working in teams make a difference. Journal of the Scholarship of Teaching and Learning, 10, 78-89.

[26] Ylvisaker, M. (1998). Collaborative brain injury intervention: positive everyday routines. San Diego: Singular Publishing Group.

[27] Ylvisaker, M., \& Feeney, T. (2000). Reconstruction of identity after brain injury. Brain Impairment, 1, 12-28.

[28] Ylvisaker, M., \& Feeney, T. (2002). Executive functions, selfregulation and learned optimism in paediatric rehabilitation: a review and implications for intervention. Pediatric Rehabilitation, 5, 51-70. 
[29] Ylvisaker, M., Adelson, P. D., Braga, L. W., Burnett, S. M. Glang, A., \& Feeney, T., et al. (2005). Rehabilitation and ongoing support after pediatric TBI: twenty years of progress. Journal of Head Trauma Rehabilitation, 20, 95-109.

[30] Ylvisaker, M., Turkstra, L., Coelho, C., Yorkston, K.,
Kennedy, M., \& Sohlberg, M., et al. (2007). Behavioural interventions for children and adults with behaviour disorders after TBI: a systematic review of the evidence. Brain Injury, $21,769-805$. 